\title{
SURVEY OF UNDERGRADUATE TEACHING OF SLEEP MEDICINE IN UK MEDICAL SCHOOLS
}

\author{
J.A. Orme ${ }^{1,2}$, S. Suresh ${ }^{3}$, D.S. Urquhart ${ }^{1,3}$ \\ ${ }^{I}$ Departments of Paediatric Respiratory and Sleep Medicine, Royal Hospital for Sick Children, \\ ${ }^{2}$ Neonatology, Simpson Centre for Reproductive Health, Edinburgh, UK, ${ }^{3}$ Departments of Paediatric \\ Respiratory and Sleep Medicine, Mater Children's Hospital, Brisbane, QLD, Australia
}

Background and aims: A 1993 survey reported that US medical schools delivered an average of only 2 hours of undergraduate sleep teaching, with $7 \%$ undertaking no teaching whatsoever. Abnormal sleep patterns have become increasingly recognised to contribute adversely to human disease and child development. Our aim was to assess whether clinical knowledge breakthroughs have led to an increase in sleep teaching.

Methods: The 1993 US study questionnaire was adapted and distributed electronically to all UK medical school undergraduate deans. Email (x2) and postal reminders were sent.

Results: Responses were received from 17/30 (57\%) medical schools, including two that refused to participate. Data were compiled on the remaining 15 responses.

A median (IQR) of $2.5(1,4.3)$ hours is spent on sleep teaching, with two universities $(13 \%)$ offering none. Areas covered include pharmacology $(80 \%)$, pathophysiology $(73 \%)$, diagnostic evaluation $(66 \%)$, daytime somnolence (47\%), developmental aspects of sleep (40\%), paediatric sleep (40\%), and polysomnography (33\%). Teaching is delivered by lectures $(87 \%)$ and tutorials $(40 \%)$ with only 1 university utilising online modules. Teachers are a mixture of medical staff (87\%), physiologists $(33 \%)$ and sleep scientists $(7 \%)$. Barriers to teaching include time (47\%), and lack of qualified faculty (13\%).

Conclusions: Despite increasing evidence that sleep plays a vital role in human health and behaviour, there is a paucity of undergraduate teaching in sleep medicine across the UK. In particular it appears that online learning is an underutilised teaching modality, yet one which might overcome the lack of faculty and teaching time available. 